\title{
BMJ Open Changes in Saturday outpatient volume and billings after introducing the Saturday incentive programme to clinics in South Korea: a longitudinal cohort study using claims data from 2012 to 2014
}

Hyun Ji Ha, ${ }^{1,2}$ Kyu-Tae Han, ${ }^{3,4}$ Sun Jung Kim, ${ }^{5}$ Tae Yong Sohn, ${ }^{6}$ Byungyool Jeon, ${ }^{7}$ Eun-Cheol Park ${ }^{8}$

To cite: Ha HJ, Han K-T, Kim SJ, et al. Changes in Saturday outpatient volume and billings after introducing the Saturday incentive programme to clinics in South Korea: a longitudinal cohort study using claims data from 2012 to 2014. BMJ Open 2016:6:e011248. doi:10.1136/bmjopen-2016011248

- Prepublication history for this paper is available online. To view these files please visit the journal online (http://dx.doi.org/10.1136/ bmjopen-2016-011248).

Received 22 January 2016 Revised 26 April 2016 Accepted 20 May 2016

CrossMark

For numbered affiliations see end of article.

Correspondence to Dr Eun-Cheol Park; ecpark@yuhs.ac

\section{ABSTRACT}

Objective: In October 2013, the South Korean government introduced an incentive programme to increase the availability of Saturday treatment at clinics, hoping to increase the role of primary care providers as gatekeepers to medical care. To the best of our knowledge, no one has yet investigated this programme's effect on overall outpatient care. Our study aims to analyse the change in Saturday outpatient volume and billings in clinics that adopted the Saturday incentive programme.

Setting: Our study used 3 types of data from the period October 2012 to March 2014: National Health Insurance Service (NHIS) claims data, hospital evaluation data and medical institution data.

Participants: These data consisted of 66825881 outpatient cases from 2837 clinics.

Interventions: Introducing the Saturday incentive programme.

Outcome measure: We performed a multilevel analysis that adjusted for clinic-level and outpatientlevel variables to examine the difference in the percentage of Saturday outpatient volume and billings after introducing the Saturday incentive programme.

Results: The percentages of Saturday outpatient volume and billings were higher after introducing the programme (outpatient volume: $\beta=2.065, p<0.001$; outpatient billings: $\beta=3.518, p<0.001$ ). In addition, outpatient volume and billings on Friday and Saturday increased after introducing the programme, while those on weekdays, excluding Friday, decreased.

Conclusions: Our findings suggest that the Saturday incentive programme has affected clinic outpatient care and is a worthwhile health policy in terms of promoting primary care. Thus, it may improve healthcare accessibility and quality of care, and prevent inappropriate usage such as emergency room visits by providing patients with weekend clinic hours.

\section{Strengths and limitations of this study}

- Our findings suggest a potential solution for promoting primary care.

- Our models considered the hierarchical nature of claims data, considering the diversity of outpatients and hospitals as much as possible.

- Data used in our study only included clinics where major treatment areas were family medicine or internal medicine.

- These results may reflect short-term effects after the adoption of the programme.

\section{INTRODUCTION}

Over the past few decades, access to medical care in South Korea has improved with the country's gradually increasing socioeconomic status and the introduction of the National Health Insurance Service (NHIS). Thanks to these changes, many more people receive needed healthcare services, and overall health status has improved substantially. However, South Korea now faces a medical expenditure problem, driven by excessive use of healthcare resources. ${ }^{2}{ }^{2}$ For example, the number of doctor consultations per capita in South Korea is highest among all Organization for Economic Cooperation and Development (OECD) countries (South Korea: 13.2 per capita in year 2011, OECD average: 6.8 per capita in year 2011). This number has gradually increased in recent years (South Korea: 11.8 in year 2005, OECD average: 6.6 in year 2005). Additionally, it is expected that healthcare expenditures will continue to increase as South Korea's population ages. ${ }^{3}$

To solve these problems, many healthcare professionals have suggested that it is 
necessary for primary care providers to act as gatekeepers for healthcare services, more efficiently managing healthcare expenditures. ${ }^{4-6}$ However, primary care visits in South Korea have declined as a result of the appearance of large hospitals. ${ }^{7}$ According to a report by the Ministry Of Health and Welfare (MOHW), the proportion of primary care expenditures relative to total healthcare expenditures has rapidly decreased $(72.1 \%$ in year 2002 to $58.7 \%$ in year 2009). ${ }^{8}$ Thus, the South Korean government has decided to introduce incentive programmes to make clinic visits, and hence primary care, more attractive.

In October, 2013, one such programme incentivising Saturday treatment in clinics was introduced. This government programme pays an additional $30 \%$ above the consultation fee to General practitioners (GPs) who provide healthcare services to outpatients on Saturday (9:00 to 13:00) in their clinics, including regular clinics, dental clinics and oriental clinics, to encourage people to visit primary care rather than visiting the hospital or emergency room (ER). The programme was initially introduced without copayment on additional cost; this was gradually changed (October 2013 to September 2014: no copayment; October 2014 to September 2015: 15\%; and after October 2015: 30\%). It was expected to influence the overall healthcare system by reducing healthcare expenditures related to ER visits for mild illness, which are often caused by insufficient time during the workweek for a patient to visit a clinic. ${ }^{9}$ Previous studies in other countries have shown incentive programmes for outpatient care or primary care to be positively associated with improvement in the quality of care, but the authors also reported some concerns about moral hazards. ${ }^{10-13}$ Nevertheless, to the best of our knowledge, although some studies on the impact of incentive programmes have been conducted by healthcare professionals and researchers, no studies have yet focused on differences in healthcare expenditure by day of the week after the incentive programme was introduced, especially with a focus on the clinic as the vehicle for primary care. Therefore, our study aims to analyse the difference in Saturday outpatient volume and billings in clinics participating in the Saturday incentive programme after the programme was introduced.

\section{MATERIALS AND METHODS}

\section{Data source and study population}

Our study used three types of data. First, we collected information on outpatient cases, using NHIS claim data from October 2012 to March 2014, from clinics that primarily specialised in internal medicine or family medicine. Of a total of 4055 clinics, we excluded those that had no Saturday outpatient cases for $>1$ month during the study period. To analyse the relationship with outpatient volume and billings while adjusting for clinic characteristics, we merged Health Insurance Review and Assessment (HIRA) hospital evaluation and medical institution data with the NHIS claim data. The data used in the final analysis consisted of 66825882 outpatient cases from 2837 clinics.

\section{Variables}

To evaluate the impact by the introduction of the Saturday incentive programme, the clinic-level outcome variables in our study were: (1) percentage of outpatient volume on Saturday relative to total weekly outpatient volume and (2) percentage of billings on Saturday relative to total weekly billings. The primary variable of interest was the introduction of the Saturday incentive programme. The programme was introduced by the South Korean government in October 2013, and it applies to clinics that provide primary care; the National Health Insurance Corporation (NHIC) pays an additional 30\% of the cost of consultation to the clinic for Saturday visits.

We adjusted for clinic-level and outpatient-level variables when analysing the relationships between the introduction of the incentive programme and the percentages of Saturday outpatient volume and billings. Clinic-level variables consisted of region type, major treatment area (family medicine or internal medicine), grade for prescription rate of antibiotics/injectable drugs, grade for kinds of prescribed drugs, age of GP, months in operation, number of nurses, outpatient volume per month and total outpatient billings per month, to consider differences by the decision-making styles or the clinic characteristics. ${ }^{14}$ Region was categorised by population size: group A consisted of metropolitan regions with more than 10 million people, such as Seoul; group B consisted of metropolitan regions with 3-10 million people; group C consisted of regions with 30 000-3 million people; and group D consisted of regions that contained $<30000$ people. We used the grades for prescription rates of antibiotics/injectable drugs and kinds of prescribed drugs to reflect the percentage of outpatients prescribed antibiotics or injection drugs, to consider quality of care in each clinic. Based on the value incentive programme, these indicators represent the level for quality of care in each clinic among all clinics in South Korea, with grade 1 indicating superior quality of care. For antibiotics, grade $1=0-40 \%$, grade $2=41-55 \%$, grade $3=56-70 \%$, grade $4=71-85 \%$ and grade $5=86-100 \%$. For injectable drugs / kinds of prescribed drugs, grade $1=0-20 \%$, grade $2=21-40 \%$, grade $3=41-60 \%$, grade $4=61-80 \%$ and grade $5=81-100 \% .{ }^{15}$ Months in operation was defined as the time since the clinic first opened and was categorised as: $<6,6$ to 10,11 to 15,16 to 20 and $>20$ months prior. Outpatient-level variables included the percentages of female outpatients and elderly ( $>60$ years of age) outpatients. ${ }^{16}$ Additionally, to analyse trends before/after introducing the incentive programme, we adjusted for month as a time variable in our multilevel analysis.

\section{Statistical analysis}

We first examined the distribution of each categorical variable, using frequencies and percentages; the average 
and SD were calculated for continuous variables. Next, to compare the difference in average values for percentage of Saturday outpatient volume and billings, we performed analyses of variance. Third, to describe an analytical approach that allows the simultaneous examination of the effects of clinic-level and outpatient-level variables on clinic-level outcomes, we performed a multilevel analysis with a mixed model procedure, analysing differences in percentage of Saturday outpatient volume and billings while adjusting for clinic-level and outpatient-level variables. ${ }^{17}$ In addition, we conducted a subgroup analysis according to the day of the week, to investigate daily differences in outpatient volume and billings after introducing the programme. Finally, to compare the impact of the Saturday incentive programme during weekdays, we also conducted additional analyses for coefficient of variability (CV) in proportion of outpatient volume or billing between weekdays. ${ }^{18}$ All statistical analyses were performed using SAS statistical software V.9.2. All $\mathrm{p}$ values were two-sided and considered significant at $\mathrm{p}<0.05$.

\section{Ethics statement}

The data used in our study consist of details of patient visits at each clinic. This study was approved by the Institutional Review Board, Yonsei University Graduate School of Public Health (2014-217). This study did not acquire informed consent from the patients, because all patient information was anonymised and de-identified prior to analysis.

\section{RESULTS}

Our data consisted of 66825881 outpatient cases from 2837 clinics. Table 1 shows the general clinic characteristics of our study sample. With regard to regional characteristics, group $\mathrm{C}$ clinics were the most common (group A: $23.1 \%$, group B: $28.1 \%$, group C: $43.1 \%$, group D: $5.7 \%)$. Internal medicine clinics $(81.6 \%)$ were more common than family medicine clinics (18.4\%). Clinics with grade 1 prescription rates were most common, as were clinics with grade 3 injectable drug and kinds of prescribed drug rates. The most frequent age band for GPs was 50-59 years, and the most common range for months in operation was 11-15. In terms of outpatient volume and billings per month, clinics with 1000-1999 visits per month were most common, as were clinics with KRW30 000 per month in billings. The percentages of female and elderly outpatients were $57.0 \%$ and $36.9 \%$, respectively.

Table 2 shows the average values and SDs of our outcome variables: percentage of Saturday outpatient volume and billings. Overall, the average percentage of Saturday outpatient volume decreased from $13.53 \%$ to $13.28 \%$, while the average proportion of Saturday billings increased from $14.00 \%$ to $15.21 \%$, after introducing the Saturday incentive programme. Outpatient billings increased after introducing the programme for both

\begin{tabular}{|c|c|c|}
\hline Variables & $\mathrm{N} / \mathrm{mean}$ & Per cent/SD \\
\hline \multicolumn{3}{|l|}{ Region } \\
\hline Group A & 656 & 23.1 \\
\hline Group B & 797 & 28.1 \\
\hline Group C & 1223 & 43.1 \\
\hline Group D & 161 & 5.7 \\
\hline \multicolumn{3}{|l|}{ Major treatment area } \\
\hline Internal medicine & 2315 & 81.6 \\
\hline Family medicine & 522 & 18.4 \\
\hline \multicolumn{3}{|l|}{ Grade: antibiotic prescription rate } \\
\hline 1 & 1377 & 48.5 \\
\hline 2 & 374 & 13.2 \\
\hline 3 & 375 & 13.2 \\
\hline 4 & 363 & 12.8 \\
\hline 5 & 348 & 12.3 \\
\hline \multicolumn{3}{|c|}{ Grade: injectable drug prescription rate } \\
\hline 1 & 213 & 7.5 \\
\hline 2 & 642 & 22.6 \\
\hline 3 & 828 & 29.2 \\
\hline 4 & 745 & 26.3 \\
\hline 5 & 409 & 14.4 \\
\hline \multicolumn{3}{|l|}{ Grade: kinds of prescribed drugs } \\
\hline 1 & 298 & 10.5 \\
\hline 2 & 471 & 16.6 \\
\hline 3 & 821 & 28.9 \\
\hline 4 & 687 & 24.2 \\
\hline 5 & 560 & 19.7 \\
\hline \multicolumn{3}{|l|}{ Age of GP (years) } \\
\hline$\leq 39$ & 80 & 2.8 \\
\hline 40 to 49 & 1241 & 43.7 \\
\hline 50 to 59 & 1130 & 39.8 \\
\hline 60 to 69 & 315 & 11.1 \\
\hline$\geq 70$ & 71 & 2.5 \\
\hline \multicolumn{3}{|l|}{ Months in operation } \\
\hline$\leq 5$ & 427 & 15.1 \\
\hline 6 to 10 & 639 & 22.5 \\
\hline 11 to 15 & 890 & 31.4 \\
\hline 16 to 20 & 414 & 14.6 \\
\hline$\geq 21$ & 467 & 16.5 \\
\hline \multicolumn{3}{|l|}{ Number of nurses } \\
\hline 0 & 2081 & 73.4 \\
\hline 1 & 482 & 17.0 \\
\hline 2 to 5 & 234 & 8.3 \\
\hline$\geq 6$ & 40 & 1.4 \\
\hline \multicolumn{3}{|l|}{ Outpatient volume (per month) } \\
\hline$\leq 999$ & 338 & 11.9 \\
\hline 1000 to 1999 & 1366 & 48.2 \\
\hline$\geq 2000$ & 1133 & 39.9 \\
\hline \multicolumn{3}{|c|}{ Total outpatient billings (KRW10 000 per month) } \\
\hline$\leq 1.999$ & 724 & 25.5 \\
\hline 2.000 to 2.999 & 927 & 32.7 \\
\hline$\geq 3.000$ & 1186 & 41.8 \\
\hline Percentage of female outpatients & 57.0 & \pm 5.6 \\
\hline Percentage of elderly outpatients & 36.9 & \pm 15.8 \\
\hline Total & 2837 & 100.0 \\
\hline
\end{tabular}

major treatment areas, though total billings for family medicine were higher than for internal medicine; there was no significant difference between the two in 
Table 2 Mean Saturday outpatient volume and billings before and after the introduction of the Saturday incentive programme

\begin{tabular}{|c|c|c|c|c|c|c|c|c|c|c|}
\hline \multirow[b]{3}{*}{ Variables } & \multicolumn{5}{|c|}{$\begin{array}{l}\text { Percentage of Saturday outpatient volume } \\
\text { Over total outpatient volume }\end{array}$} & \multicolumn{5}{|c|}{$\begin{array}{l}\text { Percentage of Saturday outpatient billings } \\
\text { Over total outpatient billings }\end{array}$} \\
\hline & \multicolumn{2}{|c|}{ Before } & \multicolumn{2}{|c|}{ After } & \multirow[b]{2}{*}{ p Value } & \multicolumn{2}{|c|}{ Before } & \multicolumn{2}{|c|}{ After } & \multirow[b]{2}{*}{ p Value } \\
\hline & Mean & SD & Mean & SD & & Mean & SD & Mean & SD & \\
\hline \multicolumn{11}{|l|}{ Region } \\
\hline Group A & 13.49 & \pm 3.62 & 13.09 & \pm 3.07 & \multirow[t]{4}{*}{0.0489} & 14.05 & \pm 3.83 & 15.10 & \pm 3.59 & \multirow[t]{4}{*}{0.0746} \\
\hline Group B & 13.88 & \pm 3.08 & 13.63 & \pm 2.63 & & 14.36 & \pm 3.29 & 15.59 & \pm 3.11 & \\
\hline Group C & 13.46 & \pm 3.13 & 13.28 & \pm 2.63 & & 13.93 & \pm 3.40 & 15.22 & \pm 3.17 & \\
\hline Group D & 12.62 & \pm 2.73 & 12.37 & \pm 2.43 & & 12.66 & \pm 2.97 & 13.78 & \pm 2.87 & \\
\hline \multicolumn{11}{|l|}{ Major treatment area } \\
\hline Internal medicine & 13.42 & \pm 3.21 & 13.14 & \pm 2.71 & \multirow[t]{2}{*}{0.0896} & 13.94 & \pm 3.48 & 15.08 & \pm 3.25 & \multirow[t]{2}{*}{0.0001} \\
\hline Family medicine & 14.00 & \pm 3.23 & 13.86 & \pm 2.81 & & 14.24 & \pm 3.37 & 15.73 & \pm 3.21 & \\
\hline \multicolumn{11}{|c|}{ Grade: antibiotic prescription rate } \\
\hline 1 & 13.41 & \pm 3.27 & 13.15 & \pm 2.79 & 0.8537 & 13.90 & \pm 3.50 & 15.08 & \pm 3.32 & 0.8977 \\
\hline 2 & 13.48 & \pm 3.09 & 13.31 & \pm 2.60 & & 13.97 & \pm 3.37 & 15.26 & \pm 3.13 & \\
\hline 3 & 13.71 & \pm 3.07 & 13.45 & \pm 2.60 & & 14.16 & \pm 3.32 & 15.38 & \pm 3.11 & \\
\hline 4 & 13.64 & \pm 3.40 & 13.32 & \pm 2.86 & & 14.06 & \pm 3.54 & 15.24 & \pm 3.30 & \\
\hline 5 & 13.78 & \pm 3.15 & 13.53 & \pm 2.68 & & 14.21 & \pm 3.42 & 15.45 & \pm 3.18 & \\
\hline Grade: injectable dr & prescrip & n rate & & & & & & & & \\
\hline 1 & 13.47 & \pm 3.51 & 13.21 & \pm 2.95 & 0.9758 & 13.99 & \pm 3.72 & 15.26 & \pm 3.45 & 0.9855 \\
\hline 2 & 13.59 & \pm 3.24 & 13.33 & \pm 2.73 & & 14.15 & \pm 3.53 & 15.33 & \pm 3.32 & \\
\hline 3 & 13.52 & \pm 3.26 & 13.30 & \pm 2.78 & & 14.02 & \pm 3.50 & 15.23 & \pm 3.31 & \\
\hline 4 & 13.52 & \pm 3.17 & 13.27 & \pm 2.70 & & 13.94 & \pm 3.35 & 15.15 & \pm 3.16 & \\
\hline 5 & 13.53 & \pm 3.07 & 13.24 & \pm 2.65 & & 13.84 & \pm 3.30 & 15.06 & \pm 3.07 & \\
\hline Grade: kinds of pres & ibed dru & & & & & & & & & \\
\hline 1 & 13.21 & \pm 3.46 & 12.99 & \pm 3.07 & 0.8134 & 13.61 & \pm 3.75 & 14.70 & \pm 3.73 & 0.1341 \\
\hline 2 & 13.49 & \pm 3.37 & 13.28 & \pm 2.84 & & 13.93 & \pm 3.61 & 15.25 & \pm 3.31 & \\
\hline 3 & 13.62 & \pm 3.17 & 13.41 & \pm 2.68 & & 14.12 & \pm 3.38 & 15.41 & \pm 3.17 & \\
\hline 4 & 13.68 & \pm 3.18 & 13.38 & \pm 2.67 & & 14.20 & \pm 3.40 & 15.39 & \pm 3.13 & \\
\hline 5 & 13.42 & \pm 3.08 & 13.13 & \pm 2.63 & & 13.84 & \pm 3.31 & 14.92 & \pm 3.13 & \\
\hline Age of GP (years) & & & & & & & & & & \\
\hline$\leq 39$ & 13.76 & \pm 3.30 & 13.62 & \pm 2.88 & 0.6081 & 14.19 & \pm 3.63 & 15.18 & \pm 3.44 & 0.6440 \\
\hline 40 to 49 & 13.72 & \pm 3.20 & 13.48 & \pm 2.73 & & 14.22 & \pm 3.47 & 15.41 & \pm 3.28 & \\
\hline 50 to 59 & 13.59 & \pm 3.20 & 13.35 & \pm 2.67 & & 14.05 & \pm 3.40 & 15.31 & \pm 3.15 & \\
\hline 60 to 69 & 12.77 & \pm 3.32 & 12.47 & \pm 2.87 & & 13.20 & \pm 3.48 & 14.42 & \pm 3.34 & \\
\hline$\geq 70$ & 12.42 & \pm 3.37 & 11.87 & \pm 2.82 & & 12.61 & \pm 3.54 & 13.65 & \pm 3.28 & \\
\hline Months in operation & & & & & & & & & & \\
\hline Up to 5 & 13.69 & \pm 3.38 & 13.38 & \pm 2.92 & 0.6423 & 14.32 & \pm 3.79 & 15.28 & \pm 3.55 & 0.0413 \\
\hline 6 to 10 & 13.60 & \pm 3.31 & 13.38 & \pm 2.85 & & 14.08 & \pm 3.53 & 15.29 & \pm 3.38 & \\
\hline 11 to 15 & 13.73 & \pm 3.17 & 13.53 & \pm 2.65 & & 14.15 & \pm 3.35 & 15.46 & \pm 3.13 & \\
\hline 16 to 20 & 13.50 & \pm 3.16 & 13.23 & \pm 2.69 & & 13.93 & \pm 3.35 & 15.12 & \pm 3.17 & \\
\hline $21+$ & 12.94 & \pm 3.14 & 12.61 & \pm 2.61 & & 13.36 & \pm 3.34 & 14.61 & \pm 3.09 & \\
\hline Number of nurses & & & & & & & & & & \\
\hline 0 & 13.60 & \pm 3.25 & 13.32 & \pm 2.78 & 0.1121 & 14.08 & \pm 3.48 & 15.34 & \pm 3.25 & 0.0249 \\
\hline 1 & 13.66 & \pm 3.21 & 13.39 & \pm 2.67 & & 14.22 & \pm 3.44 & 15.38 & \pm 3.17 & \\
\hline 2 to 5 & 12.94 & \pm 3.10 & 12.87 & \pm 2.65 & & 13.18 & \pm 3.33 & 14.24 & \pm 3.26 & \\
\hline $6+$ & 12.14 & \pm 2.76 & 12.36 & \pm 2.64 & & 11.98 & \pm 2.81 & 12.42 & \pm 2.96 & \\
\hline Outpatient volume ( & r month) & & & & & & & & & \\
\hline$\leq 999$ & 13.45 & \pm 3.77 & 13.16 & \pm 3.21 & 0.7139 & 13.90 & \pm 4.18 & 15.01 & \pm 3.91 & 0.5191 \\
\hline 1000 to 1999 & 13.66 & \pm 3.25 & 13.40 & \pm 2.76 & & 14.18 & \pm 3.48 & 15.38 & \pm 3.29 & \\
\hline$\geq 2000$ & 13.41 & \pm 3.04 & 13.19 & \pm 2.59 & & 13.82 & \pm 3.22 & 15.07 & \pm 3.01 & \\
\hline Total outpatient billir & $s(K R W$ & 000 per & onth) & & & & & & & \\
\hline$\leq 1.999$ & 13.73 & \pm 3.55 & 13.41 & \pm 3.04 & 0.2584 & 14.18 & \pm 3.80 & 15.48 & \pm 3.54 & 0.0371 \\
\hline 2.000 to 2.999 & 13.74 & \pm 3.20 & 13.47 & \pm 2.66 & & 14.27 & \pm 3.41 & 15.54 & \pm 3.11 & \\
\hline$\geq 3.000$ & 13.26 & \pm 3.05 & 13.07 & \pm 2.62 & & 13.70 & \pm 3.30 & 14.80 & \pm 3.16 & \\
\hline Total & 13.53 & \pm 3.24 & 13.28 & \pm 2.75 & & 14.00 & \pm 3.47 & 15.21 & \pm 3.26 & \\
\hline
\end{tabular}


outpatient volume. Also, when analysed by months in operation, average outpatient billings increased after introducing the incentive programme, with recently opened clinics displaying a stronger trend. These relationships were also analysed in terms of average Saturday outpatient billings relative to total outpatient billings. Clinics with lower total outpatient billings had higher percentages of Saturday outpatient billings.

Table 3 shows the results of our multilevel analysis assessing the difference in percentages of Saturday outpatient volume and billings after introducing the Saturday incentive programme, while adjusting for clinic-level and outpatient-level characteristics. Percentage of Saturday outpatient volume was higher after introducing the programme $(\beta=2.065, \mathrm{p}<0.001)$. The number of months before the programme was introduced at a clinic was associated with higher Saturday outpatient volume, and the number of months after introducing the programme was inversely associated with Saturday outpatient volume. The percentage of Saturday outpatient volume was higher for group B than for group A clinics, and group D clinics had lower volume than group A clinics. Also, family medicine clinics had a greater percentage of Saturday outpatient volume than did internal medicine clinics (family medicine: $\beta=0.337, p<0.05$; ref=internal medicine). With regard to antibiotic prescription rates, grade 5 clinics had higher Saturday outpatient volume than did grade 1 clinics. GP age was also associated with Saturday outpatient volume ( $\leq 39$ years $=$ ref; $40-49$ years: $\beta=-0.096$, $\mathrm{p}=0.6954 ; 50-59$ years: $\beta=-0.139, \mathrm{p}=0.5866 ; 60-69$ years: $\beta=-0.631, p<0.05 ; \geq 70$ years: $\beta=-1.045, p<0.05)$. Clinics with billings of KRW $>30000$ per month had a higher percentage of Saturday outpatient volume. Finally, a higher percentage of female patients was positively associated with Saturday outpatient volume $(\beta=0.036, p<0.001)$, while the percentage of elderly outpatients was inversely associated with percentage of Saturday outpatient volume $(\beta=-0.020, p<0.001)$.

Similar to the results for Saturday outpatient volume, Saturday outpatient billings were higher after introducing the incentive programme $(\beta=3.518, \quad p<0.001)$. Likewise, the results for months before/after introducing the programme, regional characteristics and antibiotic prescription grades, were all similar to those for Saturday outpatient volume. The percentage of Saturday outpatient billings was higher for clinics with a $\mathrm{GP} \geq 70$ years of age than those with a younger GP. Also, a higher percentage of female outpatients was positively associated with Saturday outpatient billings $(\beta=0.045$, $\mathrm{p}<0.001)$. However, the percentage of elderly patients was inversely associated with the percentage of Saturday outpatient billings $(\beta=-0.029, \mathrm{p}<0.001)$.

We also performed a subgroup analysis by day of the week, to investigate daily differences in outpatient volume and billings after introducing the programme. Outpatient volume on Friday and Saturday increased after introducing the programme, while volume on weekdays, excluding Friday, decreased. Similarly, outpatient billings for Friday and Saturday increased, while billings on non-Friday weekdays decreased (figures 1 and 2). Furthermore, we conducted additional analyses for $\mathrm{CV}$ in proportion of outpatient volume or billing during weekdays, to identify whether the Saturday incentive programme had positive association with distribution of outpatient care during weekdays. Based on the results, there was positive association with even distribution between weekdays after introduction of the Saturday incentive programme (CV for outpatient volume, after introducing programme $=\beta$ : $\quad-5573$, $\mathrm{p}<0.001$; CV for outpatient billing, after introducing programme $=\beta:-5.123, \mathrm{p}<0.001)$.

\section{DISCUSSION}

To investigate the impact of the Saturday programme on outpatient usage, we analysed the difference in outpatient visits after the programme was introduced, focusing on Saturday outpatient volume and billings. Our results showed that the Saturday incentive programme was associated with changes in the behaviour of clinics and outpatients. Saturday outpatient volume and billings increased after the programme was adopted. Therefore, our findings indicate that the Saturday incentive programme has induced GPs to provide healthcare services in their clinics on Saturday, thus changing the daily distribution of outpatient visits, which, in the past, was concentrated on weekdays. Such changes are worthwhile from the perspective of health policy.

Although healthcare accessibility has improved in recent years, many people who require healthcare services cannot obtain them on weekdays, because work does not allow them sufficient time to visit a medical institution. ${ }^{19} 20$ Accordingly, people have often visited the ER on weekends as an alternative means of obtaining healthcare, despite experiencing only mild illness. ${ }^{9}$ Such health-seeking behaviours have continuously increased healthcare expenditures in South Korea. Thus, the improved accessibility provided by the Saturday incentive programme could reduce the unmet need for weekend clinic hours in South Korean workers.

However, there may be possible unintended effects such as moral hazards or physician-induced demand by the introduction of the Saturday incentive programme, as seen in some other financial incentive programmes. Nevertheless, continued consideration must be given to improving South Korean healthcare via health policies such as the Saturday incentive programme. During the study period, the Saturday incentive programme increased payment for clinics without increasing patient co-insurance. However, the South Korean government increased the patients' charges after October 2015. Such a change is expected to cause controversy regarding moral hazards and reduced health equity. For that reason, further studies on the effect of adding a patient charge are needed.

In addition, based on the results of our study, the CV between weekdays was decreased after introducing the 
Table 3 Results of a multilevel analysis: percentage of Saturday outpatient volume and billings before and after the introduction of the Saturday incentive programme

\begin{tabular}{|c|c|c|c|c|}
\hline \multirow[b]{2}{*}{ Variables } & \multicolumn{2}{|c|}{$\begin{array}{l}\text { Percentage of Saturday } \\
\text { outpatient volume over total } \\
\text { outpatient volume }\end{array}$} & \multicolumn{2}{|c|}{$\begin{array}{l}\text { Percentage of Saturday } \\
\text { outpatient billings over total } \\
\text { outpatient billings }\end{array}$} \\
\hline & $\beta$ & p Value & $\beta$ & p Value \\
\hline \multicolumn{5}{|l|}{ Programme } \\
\hline Before introducing programme & Ref & - & Ref & - \\
\hline After introducing programme & 2.065 & $<0.0001$ & 3.518 & $<0.0001$ \\
\hline \multicolumn{5}{|l|}{ Time (months) } \\
\hline Before introducing programme & 0.659 & $<0.0001$ & 0.662 & $<0.0001$ \\
\hline After introducing programme & -0.065 & $<0.0001$ & -0.068 & $<0.0001$ \\
\hline \multicolumn{5}{|l|}{ Region } \\
\hline Group A & Ref & - & Ref & - \\
\hline Group B & 0.545 & $<0.0001$ & 0.520 & 0.0004 \\
\hline Group C & 0.175 & 0.1695 & 0.178 & 0.2046 \\
\hline Group D & -0.380 & 0.0258 & -0.693 & 0.0004 \\
\hline \multicolumn{5}{|l|}{ Major treatment area } \\
\hline Internal medicine & Ref & - & Ref & - \\
\hline Family medicine & 0.337 & 0.0004 & 0.129 & 0.2340 \\
\hline \multicolumn{5}{|l|}{ Grade: antibiotic prescription rate } \\
\hline 1 & Ref & - & Ref & - \\
\hline 2 & 0.032 & 0.7518 & 0.044 & 0.7116 \\
\hline 3 & 0.137 & 0.1542 & 0.090 & 0.4253 \\
\hline 4 & 0.037 & 0.7701 & -0.013 & 0.9253 \\
\hline 5 & 0.258 & 0.0183 & 0.264 & 0.0378 \\
\hline \multicolumn{5}{|c|}{ Grade: injectable drug prescription rate } \\
\hline 1 & Ref & - & Ref & - \\
\hline 2 & 0.124 & 0.4398 & 0.119 & 0.5137 \\
\hline 3 & -0.051 & 0.7488 & -0.121 & 0.5020 \\
\hline 4 & -0.126 & 0.4357 & -0.248 & 0.1719 \\
\hline 5 & -0.016 & 0.9248 & -0.171 & 0.3723 \\
\hline \multicolumn{5}{|l|}{ Grade: kinds of prescribed drugs } \\
\hline 1 & Ref & - & Ref & - \\
\hline 2 & -0.008 & 0.9599 & 0.064 & 0.7268 \\
\hline 3 & 0.114 & 0.4322 & 0.220 & 0.1861 \\
\hline 4 & 0.179 & 0.2290 & 0.311 & 0.0684 \\
\hline 5 & 0.091 & 0.5658 & 0.171 & 0.3499 \\
\hline \multicolumn{5}{|l|}{ Age of GP (years) } \\
\hline$\leq 39$ & Ref & - & Ref & - \\
\hline 40 to 49 & -0.096 & 0.6954 & 0.141 & 0.6251 \\
\hline 50 to 59 & -0.139 & 0.5866 & 0.082 & 0.7829 \\
\hline 60 to 69 & -0.631 & 0.0295 & -0.396 & 0.2392 \\
\hline$\geq 70$ & -1.045 & 0.0052 & -0.989 & 0.0212 \\
\hline \multicolumn{5}{|l|}{ Months in operation } \\
\hline$\leq 5$ & Ref & - & Ref & - \\
\hline 6 to 10 & 0.136 & 0.2954 & 0.079 & 0.5976 \\
\hline 11 to 15 & 0.266 & 0.0283 & 0.207 & 0.1360 \\
\hline 16 to 20 & 0.070 & 0.6338 & 0.026 & 0.8770 \\
\hline$\geq 21$ & -0.202 & 0.2206 & -0.217 & 0.2497 \\
\hline \multicolumn{5}{|l|}{ Number of nurses in clinic } \\
\hline 0 & Ref & - & Ref & - \\
\hline 1 & 0.016 & 0.8639 & 0.019 & 0.8566 \\
\hline 2 to 5 & -0.313 & 0.0198 & -0.759 & $<0.0001$ \\
\hline$\geq 6$ & -0.350 & 0.3875 & -1.458 & 0.0017 \\
\hline \multicolumn{5}{|l|}{ Outpatient volume (per month) } \\
\hline$\leq 999$ & Ref & - & Ref & - \\
\hline 1000 to 1999 & 0.044 & 0.7783 & 0.116 & 0.5276 \\
\hline \multirow[t]{2}{*}{$\geq 2000$} & 0.057 & 0.7654 & 0.101 & 0.6563 \\
\hline & & & & Continued \\
\hline
\end{tabular}


Table 3 Continued

\begin{tabular}{|c|c|c|c|c|}
\hline \multirow[b]{2}{*}{ Variables } & \multicolumn{2}{|c|}{$\begin{array}{l}\text { Percentage of Saturday } \\
\text { outpatient volume over total } \\
\text { outpatient volume }\end{array}$} & \multicolumn{2}{|c|}{$\begin{array}{l}\text { Percentage of Saturday } \\
\text { outpatient billings over total } \\
\text { outpatient billings }\end{array}$} \\
\hline & 及 & p Value & 及 & p Value \\
\hline \multicolumn{5}{|c|}{ Total outpatient billings (KRW10 000 per month) } \\
\hline$\leq 1.999$ & Ref & - & Ref & - \\
\hline 2.000 to 2.999 & -0.176 & 0.1159 & -0.196 & 0.1250 \\
\hline$\geq 3.000$ & -0.684 & $<0.0001$ & -0.830 & $<0.0001$ \\
\hline Percentage of female outpatients & 0.036 & $<0.0001$ & 0.045 & $<0.0001$ \\
\hline Percentage of elderly outpatients & -0.020 & $<0.0001$ & -0.029 & $<0.0001$ \\
\hline
\end{tabular}

programme. Therefore, it suggested that the introduction of this programme could positively affect even distribution of outpatient cases compared with that before the programme, as well as increases in the proportion of Saturday outpatient cases, and it may also reduce the workload of healthcare providers by reducing the concentration of outpatient visits on weekdays. ${ }^{21}$ This is expected to make outpatient treatment more efficient, and thus improve quality of care in South Korea. Therefore, policies such as the Saturday incentive programme could be helpful in managing healthcare quality and expenditures in South Korea. ${ }^{22}$

Our study has several strengths. First, the data used in our study included nationwide outpatient clinic cases from before and after the introduction of the programme. Thus, our findings are generalisable to South Korea as a whole, and would be helpful in establishing health policies and revising established health policies to improve efficiency. Second, we used multilevel modelling to adjust for outpatient-level and clinic-level characteristics. ${ }^{23}{ }^{24}$ In our study, the percentage of female/elderly outpatients was related to healthcare expenditures. Given these results, it may be possible to create policies that

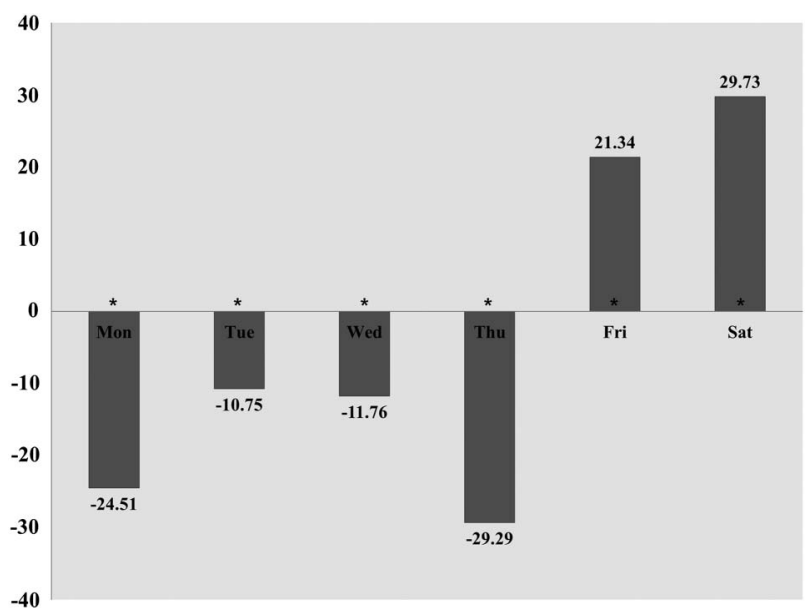

Figure 1 Changes in outpatient volume by day of the week after introducing the Saturday incentive programme. Results of multilevel analysis adjusted for clinic-level and outpatient-level characteristics. ${ }^{*} p<0.05$. differ based on outpatient characteristics. Our study also has several limitations. First, the data used in our study only included clinics where major treatment areas were family medicine or internal medicine. Thus, our findings cannot be applied to other types of clinics. Second, we could not have access to outpatient care details, such as diagnoses, type of care, etc, because these data were not present in our data set. Thus, it would be desirable to conduct additional studies with more detailed data. Third, the number of months that elapsed before and after the incentive programme was adopted was positively and negatively associated with outpatient visits, respectively, in our study. However, it was difficult to interpret these findings. These results may reflect short-term effects after the adoption of the programme; however, more detailed, long-term analyses are required to explore this finding. Fourth, we only considered clinic outpatient visits, because the data used in this study only included the information about outpatient cases rather than overall information such as ER visits or inpatient care. For that reason, our findings could not consider the healthcare usage through ER visits or hospitalisation. Also, it is difficult to determine whether the incentive

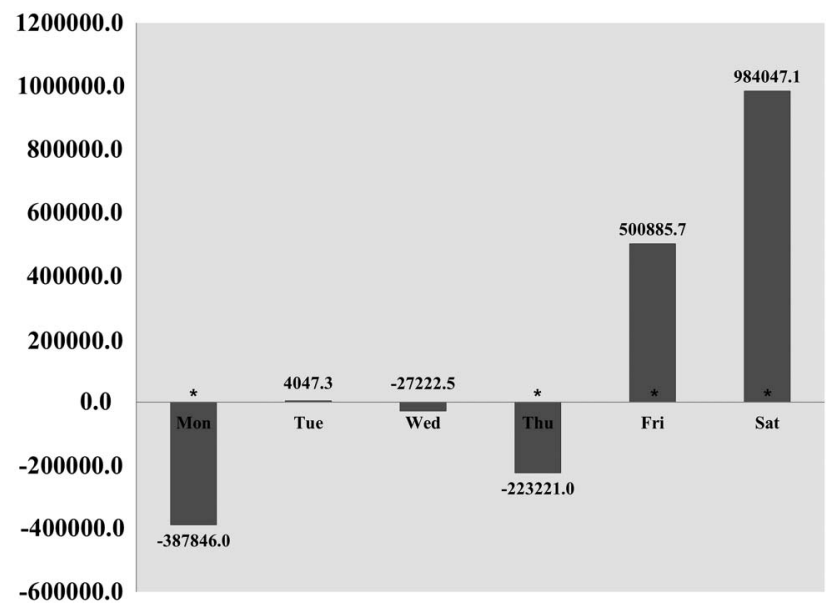

Figure 2 Changes in outpatient billings by day of the week after introducing the Saturday incentive programme. Results of multilevel analysis adjusted for clinic-level and outpatient-level characteristics. ${ }^{*} \mathrm{p}<0.05$. 
programme was effective at reducing healthcare expenditures by facilitating primary care provision, because it has introduced an element of moral hazard into the use of healthcare. Therefore, detailed analyses of the effect of introducing the programme, including factors such as hospital, inpatient care or ER visits, are needed in the future. Fifth, we could not consider the impact of changes in copayment for outpatient care after October 2014, due to limitation of data. Thus, conducting of further studies using data including the changes of copayment has to be considered in the near future. Finally, in many other studies on the introduction of new programmes, there were systematic programme evaluation methodologies such as the logical model, but we could not adopt such a model due to limitation of data, which not included any activity or process. ${ }^{25} 26$ Nevertheless, our findings suggest that the Saturday incentive programme has affected clinic outpatient care and is a worthwhile health policy in terms of promoting primary care. Based on our results, healthcare professionals and health policymakers should consider additional alternatives for promoting primary care in South Korea. However, more detailed studies using bigger, more detailed datasets are needed to determine effective strategies.

\section{CONCLUSIONS}

The introduction of the Saturday incentive programme appears to have increased the provision of outpatient care on Saturdays. Thus, it may improve healthcare accessibility and quality of care, and prevent inappropriate usage such as ER visits by providing patients with weekend clinic hours.

\section{Author affiliations}

${ }^{1}$ Department of Health Policy and Management, Graduate School of Public Health, Yonsei University, Seoul, Republic of Korea

${ }^{2}$ Health Insurance Review and Assessment Service, Seoul, Republic of Korea ${ }^{3}$ Department of Public Health, Graduate School, Yonsei University, Seoul, Republic of Korea

${ }^{4}$ Institute of Health Services Research, Yonsei University College of Medicine, Seoul, Republic of Korea

${ }^{5}$ Department of Health Administration and Management, Soonchunhyang University, Asan, Republic of Korea

${ }^{6}$ Department of Health Services Administration, Yuhan University, Bucheon, Republic of Korea

${ }^{7}$ Department of Preventive Medicine, CHA University College of Medicine, Pocheon, Republic of Korea

${ }^{8}$ Department of Preventive Medicine, Yonsei University College of Medicine, Seoul, Republic of Korea

Contributors HJH and K-TH designed the study, researched the data, performed the statistical analyses and wrote the manuscript. SJK, TYS, BJ and E-CP contributed to the discussion and reviewed and edited the manuscript. E-CP is the guarantor of this work and, as such, had full access to all the data in the study, and takes responsibility for the integrity of the data and the accuracy of the data analysis.

Funding This research received no specific grant from any funding agency in the public, commercial or not-for-profit sectors.

Competing interests None declared.

Ethics approval This study was approved by the Institutional Review Board, Yonsei University Graduate School of Public Health (2014-217).
Provenance and peer review Not commissioned; externally peer reviewed.

Data sharing statement No additional data are available.

Open Access This is an Open Access article distributed in accordance with the Creative Commons Attribution Non Commercial (CC BY-NC 4.0) license, which permits others to distribute, remix, adapt, build upon this work noncommercially, and license their derivative works on different terms, provided the original work is properly cited and the use is non-commercial. See: http:// creativecommons.org/licenses/by-nc/4.0/

\section{REFERENCES}

1. Lu JF, Leung GM, Kwon S, et al. Horizontal equity in health care utilization evidence from three high-income Asian economies. Soc Sci Med 2007;64:199-212.

2. Park E-C, Jang S-I. The diagnosis of healthcare policy problems in Korea. J Korean Med Assoc 2012;55:932-9.

3. Organization for Economic Cooperation and Development. Health at a glance 2013. OECD Indicators, 2013.

4. Starfield B, Shi L, Macinko J. Contribution of primary care to health systems and health. Milbank Q 2005;83:457-502.

5. Starfield B. Is primary care essential? Lancet 1994;344:1129-33.

6. Costello EJ, Burns BJ, Costello AJ, et al. Service utilization and psychiatric diagnosis in pediatric primary care: The role of the gatekeeper. Pediatrics 1988;82:435-41.

7. Kwon S. Thirty years of national health insurance in South Korea: lessons for achieving universal health care coverage. Health Policy Plan 2009;24:63-71.

8. Ministry of Health \& Welfare. Internal report: share and medical cost by types of medical institution. 2013.

9. Kim J, Ko S, Yang B. The effects of patient cost sharing on ambulatory utilization in South Korea. Health Policy 2005;72:293-300.

10. Hillman AL, Pauly MV, Kerstein JJ. How do financial incentives affect physicians' clinical decisions and the financial performance of health maintenance organizations? N Engl J Med 1989;321:86-92.

11. Rosenthal MB, Dudley RA. Pay-for-performance: will the latest payment trend improve care? JAMA 2007;297:740-4.

12. Campbell SM, Reeves D, Kontopantelis E, et al. Effects of pay for performance on the quality of primary care in England. $N$ Engl $J$ Med 2009;361:368-78.

13. Hellinger FJ. The impact of financial incentives on physician behavior in managed care plans: a review of the evidence. Med Care Res Rev 1996;53:294-314.

14. Bhosle M, Samuel S, Vosuri V, et al. Physician and patient characteristics associated with outpatient breast cancer screening recommendations in the United States: analysis of the National Ambulatory Medical Care Survey Data 1996-2004. Breast Cancer Res Treat 2007;103:53-9.

15. Kim SM, Jang WM, Ahn HA, et al. Korean National Health Insurance value incentive program: achievements and future directions. J Prev Med Public Health 2012;45:148-55.

16. Hoover KW, Tao G, Berman S, et al. Utilization of health services in physician offices and outpatient clinics by adolescents and young women in the United States: implications for improving access to reproductive health services. J Adolesc Health 2010;46:324-30.

17. Hox JJ, Moerbeek M, van de Schoot R. Multilevel analysis: techniques and applications. Routledge, 2010.

18. Martinez-Pons M. A coefficient of variability. J Math Stat 2013;9:62

19. Lee S-Y, Kim C-W, Kang J-H, et al. Unmet healthcare needs depending on employment status. Health Policy 2015;119:899-906.

20. Kim J, Kim TH, Park E-C, et al. Factors influencing unmet need for health care services in Korea. Asia Pac J Public Health 2015;27: NP2555-69.

21. Hong du $\mathrm{P}$, Song J. The effective distribution system for the concentration of patients to extra-large hospitals. J Korean Surg Soc 2011;80:373-83.

22. Shirom A, Nirel N, Vinokur AD. Overload, autonomy, and burnout as predictors of physicians' quality of care. J Occup Health Psychol 2006;11:328.

23. Snijders TA. Multilevel analysis. Springer, 2011.

24. Leyland $\mathrm{AH}$, Goldstein $\mathrm{H}$. Multilevel modelling of health statistics. Wiley, 2001

25. Julian DA, Jones A, Deyo D. Open systems evaluation and the logic model: program planning and evaluation tools. Eval Program Plann 1995;18:333-41.

26. Julian DA. The utilization of the logic model as a system level planning and evaluation device. Eval Program Plann 1997;20:251-7. 
Correction: Changes in Saturday outpatient volume and billings after introducing the Saturday incentive programme to clinics in South Korea: a longitudinal cohort study using claims data from 2012 to 2014

Ha HJ, Han K-T, Kim SJ, et al. Changes in Saturday outpatient volume and billings after introducing the Saturday incentive programme to clinics in South Korea: a longitudinal cohort study using claims data from 2012 to 2014. BMJ Open 2016;6: e011248. The following statement should be included in this paper: H-HC and K-TH contributed equally to this work and should be considered co-first authors.

Open Access This is an Open Access article distributed in accordance with the Creative Commons Attribution Non Commercial (CC BY-NC 4.0) license, which permits others to distribute, remix, adapt, build upon this work noncommercially, and license their derivative works on different terms, provided the original work is properly cited and the use is non-commercial. See: http://creativecommons.org/licenses/by-nc/4.0/

BMJ Open 2016;6:e011248corr1. doi:10.1136/bmjopen-2016-011248corr1 